\title{
SUPERMERCADOS FAMINTOS, MERCADOS LOCAIS RESISTENTES: A DINÂMICA LATINO- AMERICANA E O COMPORTAMENTO DO MERCADO BRASILEIRO
}

\author{
Altivo Roberto Andrade de Almeida Cunha \\ Food and Agriculture Organization - FAO/ONU \\ altivo.cunha@gmail.com \\ Mauro Macedo Campos \\ Universidade Estadual do Norte Fluminense Darcy Ribeiro (UENF) \\ Programa de Pós-Graduação em Sociologia Política - PPGSP \\ Laboratório de Gestão e Políticas Públicas - LGPP \\ mauromcampos@pq.cnpq.br
}

\begin{abstract}
RESUMO
$\mathrm{O}$ artigo analisa o processo de mudança das fontes e mecanismos de abastecimento alimentar na América Latina, a partir de pesquisa realizada em parceria com a FAO. A perda de importância dos mercados públicos no abastecimento urbano caminha pari passu com o sucesso dos supermercados que ganham espaço no abastecimento alimentar nesses países, em contraponto aos mercados atacadistas. A expansão dos supermercados teve como consequência a perda de espaço comercial de mercados tradicionais e as feiras de rua. Essas mudanças representam desafios com a exclusão de pequenos agricultores e estabelecimentos de varejo, mas sinalizam oportunidades de inserção comercial sob novos padrões de consumo, como a agregação de valor baseada no registro de origem, na préclassificação, na rastreabilidade ambiental e social e na revalorização de mercados locais como equipamentos urbanos de alimentação e lazer. Este artigo é resultado de pesquisa financiada pelo Projeto de Educação Ambiental (PEA) Pescarte que é uma medida de mitigação exigida pelo Licenciamento Ambiental Federal, conduzido pelo IBAMA.
\end{abstract}

Palavras-Chave: Abastecimento alimentar. América Latina. Supermercados. Novos padrões de consumo. Mercados tradicionais.

\section{HUNGRY SUPERMARKETS, RESISTANT LOCAL MARKETS: THE LATIN AMERICAN DYNAMICS AND THE BEHAVIOR OF THE BRAZILIAN MARKET}

\begin{abstract}
This article analyses the gradual process of change in the food supply mechanisms in Latin America, based on research conducted in partnership with FAO. The loss of importance of public markets in urban supply is pari passu with the success of supermarkets in counterpoint to wholesaler markets. The expansion of supermarkets in Latin American countries had the consequence of the loss of space and commercial importance of traditional markets and outdoor markets. These changes pose challenges, with the exclusion of small farmers and retail establishments, but also signalize opportunities for commercial insertion under new consumption patterns, such as aggregation of value based on registration of origin, pre-classification, environmental traceability and social relations and the revaluation of local markets as urban food and leisure equipment. This paper is the result of research funded by the Pescarte Environmental Education Project (PEA), which is a mitigation measure required by the Federal Environmental Licensing, conducted by IBAMA.
\end{abstract}

Keywords: Food supply. Latin America. Supermarkets. New consumption patterns. Traditional markets.

\section{INTRODUÇÃO}

A estrutura do varejo de alimentos na América Latina se insere em um sistema alimentar complexo e em transformação constante, movimentando um conjunto amplo de recursos cuja dinâmica afeta diretamente a capacidade e o perfil do consumo. Afinal, os gastos com produtos alimentícios têm um

$\begin{array}{llllll}\text { Caminhos de Geografia } & \text { Uberlândia-MG } & \text { v. 23, n. } 85 & \text { fev./2022 } & \text { p. 88-101 } & \text { Página } 88\end{array}$


peso expressivo nos orçamentos familiares, sobretudo naquelas com menor poder aquisitivo, chegando comprometer cerca de um terço do orçamento doméstico, em diversos países da América Latina (SOUZA, 2013; BEZERRA et al, 2017).

Nas últimas décadas, a maioria dos países latino-americanos adotou programas e ações de cooperação internacional, baseadas em programas e políticas públicas de transferência condicionada de renda e em programas focalizados de combate à desnutrição (SOARES e SÁTYRO, 2009; BICHIR, 2010; SILVA e PONTES, 2018). Na contramão dessas iniciativas, ações para o aprimoramento e desenvolvimento de equipamentos e canais de abastecimento alimentar foram deixadas de lado. Os problemas relacionados às políticas públicas de abastecimento urbano passaram a ser considerados pela ótica da eficiência logística, a partir de elementos como o transporte, a armazenagem e a distribuição (MALUF, 2012). E por essa lógica, o que se tem como padrão dominante acaba sendo ditado pelas grandes redes de supermercados, com a prevalência de incentivos e de coordenação de cadeias produtivas (CUNHA, 2015). A adoção desse formato de relações pautado em incentivos, por sua vez, induz ao aumento da escala de aquisição através de centros de distribuição que compram produtos de áreas geográficas ampliadas, para atender a um grande número de pontos de venda, o que exige modernas técnicas de gestão, informação e negociação (POPKIN, 2014; REARDON, 2015).

O setor supermercadista, por tratar-se de um segmento oligopolizado e caracterizado pela pressão concorrencial tende a operar com margens reduzidas, ganhos de escala, e com redução de custos de produção e de transação. Faz parte de uma estrutura de mercado com elevada sensibilidade à variação de preços praticados pelos concorrentes e as estratégias de marketing que adotam. Além da adoção de estruturas enxutas de coordenação, que envolve a gestão de contratos, estoques e informações, que se moldam conforme a necessidade e o padrão de concorrência.

Por lidarem proximamente com uma gama de fornecedores, o setor supermercadista estabelece os seus próprios padrões de negociação. No caso de hortifrutícolas, e outros oriundos de produtores rurais e atacadistas, o processo de negociação com estes fornecedores perpassa, basicamente por barganhas de preços, além de estabelecerem normas privadas para especificação da qualidade, segurança, volume e embalagem do produto. No entanto, dada as condições que se estabelecem nas relações comerciais entre estes fornecedores e as redes de supermercados, tais "vantagens concorrenciais" inseridas aos produtos, não se refletem propriamente em ganhos financeiros, apenas os mantém no rol de fornecedores daquela rede. Assim, a suposta vantagem competitiva atrelada ao caráter socioambiental e cultural, atribuída aos pequenos produtores agrícolas cai por terra e tende a se anular, imersa no arcabouço mercadológico das grandes redes de supermercados.

O debate sobre a política de abastecimento urbano, a partir do avanço irreversível do setor supermercadista, parte de três questões principais. A primeira é a capacidade de inclusão de produtores rurais, especialmente agricultores familiares nesse circuito de distribuição. $O$ modelo adotado pelos supermercados para a realização de compras é normatizado e tem por base, padrões técnicos, em termos de escala e de condições comerciais e de fornecedores. Esse caráter técnico e formalizado representa um entrave aos agricultores familiares que não dispõem de tais procedimentos. Em termos práticos, a maior parte desses agricultores não consegue participar deste canal de comercialização em função destes requisitos. Esta seletividade afeta diretamente a diversidade da pauta de oferta de produtos regionais ou típicos que ainda não lograram alcançar uma escala comercial ou técnica. E já são apontadas em algumas experiências internacionais, que ressaltam condições de exclusão de produtores em grandes cidades como Chicago, nos Estados Unidos (REARDON, 2015) e Turim, na Itália (BOTTIGLIERI et al, 2016).

A segunda questão, presente no atual debate sobre o abastecimento urbano diz respeito ao processo competitivo, que nesse caso, incorpora outros estabelecimentos varejistas, como feiras livres, pequenos mercados, mercados municipais e centrais de abastecimento que têm função varejista (MENEZES; PORTO; GRISA, 2015; COCATO, 2020). Esse conjunto plural de estabelecimentos atende clientelas específicas no meio urbano e ainda são bastante relevantes nos países da América Latina.

A terceira questão está relacionada às alternativas de consumo que se contrapõem ao sistema predominante de cadeias de fornecimento longas e centralizadas pela aliança agroindustrial-grande varejo. São formas alternativas de acesso e amplitude dos quesitos de preferência atribuídos aos alimentos, por meio de canais curtos de comercialização cuja importância materializa-se na possibilidade de identificação do produto e produtor, bem como a valorização dos aspectos locais da

$\begin{array}{lllll}\text { Caminhos de Geografia } & \text { Uberlândia-MG } & \text { v. 23, n. } 85 & \text { fev./2022 } & \text { p. 88-101 Página } 89\end{array}$


produção e o uso de canais alternativos de venda direta da produção (CEPAL, 2013; SACCO DOS ANJOS e CALDAS, 2017).

Como se sabe, os consumidores não possuem, isoladamente, condições para ordenar o sistema produtivo e ditar a oferta de alimentos, conforme suas necessidades e desejos. As suas preferências ficam restritas ao que é ofertado pelos supermercados e, dada a concentração deste setor, é difícil encontrar produtos alternativos àqueles do mix comercializado pelas grandes redes (CUNHA, 2015). Em muitos casos, a escolha da pauta de produtos ofertados pelos supermercados sugere uma estratégia de aliança do grande varejo com as agroindústrias alimentares para promover e elevar o consumo dos chamados "produtos saborosos", com altos teores de gorduras, açúcares e sódio (MENEZES; PORTO; GRISA, 2015). No entanto, também, não são decisões inócuas. E, neste sentido, a pandemia da obesidade e de hipertensão, por exemplo, colocou o abastecimento urbano como essencialmente uma questão de saúde pública, cujas alternativas têm se restringido à promoção de hábitos de consumo adequados e a pactuação com as grandes redes de distribuição para oferecer um conjunto de produtos mais saudáveis (MALIK et al, 2013; Viola, 2013; KIMENJU et al, 2015).

Por fim, nos últimos anos tem sido observada uma mudança no mix de oferta de supermercados, com a ampliação da oferta de produtos frescos, como frutas, legumes e verduras, produtos orgânicos e produtos "naturais" dentro da lógica de suprimentos do canal supermercadista. Trata-se de uma guinada em direção à última onda relativa à política pública de abastecimento urbano, como forma de conviver com predomínio inconteste dos supermercados. A análise desse ambiente complexo e interligado é o que se pretende dar conta nesse artigo.

\section{OS SUPERMERCADOS NO CONTEXTO LATINO-AMERICANO DE ABASTECIMENTO ALIMENTAR}

Os supermercados são protagonistas no fornecimento alimentar da maioria dos países da América Latina. Essas mudanças representam grandes desafios, como a exclusão dos pequenos agricultores e estabelecimentos de varejo, mas também oportunidades inserção comercial sob os novos padrões de consumo.

A tabela 1 evidencia a participação dos supermercados no comércio varejista de alimentos nos países latino-americanos. Os dados apontam uma variação entre $45 \%$ a $75 \%$ nos países de renda mais elevada, como Argentina, Brasil, Chile, Colômbia, Costa Rica e México, que agregadamente representavam $86 \%$ da receita e $74 \%$ da população da América Latina (REARDON e BERDEGUÉ, 2002). No entanto, esse crescimento dos supermercados não está restrito aos maiores países, tendo também, representatividade em países com menores taxas de urbanização, população e renda.

Tabela 1 - Participação dos supermercados no setor varejista de alimentos: países selecionados de América Latina (ano de referência, 2001).

\begin{tabular}{ccccc}
\hline Países & $\begin{array}{c}\text { Participação dos supermercados no } \\
\text { comércio varejista de alimentos (\%) }\end{array}$ & $\begin{array}{c}\text { Renda per capita } \\
\text { (U\$1.000) }\end{array}$ & $\begin{array}{c}\text { População (em } \\
\text { milhões) }\end{array}$ & $\begin{array}{c}\text { Urbanização 2002 } \\
\text { (\%) }\end{array}$ \\
\hline Argentina & 57 & 7.500 & 37 & 89,9 \\
Brasil & 75 & 3.600 & 170 & 82,4 \\
Chile & 50 & 4.600 & 15 & 86,6 \\
Colômbia & 38 & 2.000 & 42 & 76,0 \\
Costa Rica & 50 & 3.800 & 4 & 60,1 \\
El Salvador & 37 & 2.000 & 6 & 59,3 \\
Guatemala & 35 & 1.700 & 11 & 45,9 \\
Honduras & 42 & 900 & 6 & 45,2 \\
México & 45 & 5.100 & 98 & 75,2 \\
Panamá & 54 & 3.300 & 3 & 56,8
\end{tabular}

Fonte - Reardon e Berdegué (2002); Traill (2006). Elaboração e adaptação dos autores.

$\begin{array}{lllll}\text { Caminhos de Geografia } & \text { Uberlândia-MG } & \text { v. 23, n. } 85 & \text { fev./2022 } & \text { p. 88-101 }\end{array}$ 
A expansão dos supermercados na América Latina, de acordo com os autores, acelerou-se a partir da década de 1980 em direção a cidades intermediárias e na década de 1990 para cidades menores, expandindo-se também, no tecido urbano, com a disseminação de supermercados dos bairros de alta renda para bairros periféricos e de baixa renda. É um cenário, onde as multinacionais têm sido a força dominante no setor supermercadista latino-americano, com a dinâmica dos padrões de crescimento sendo estabelecida pelos investimentos de gigantes globais, como a Wal-Mart, Carrefour e Ahold, a partir da segunda metade dos anos de 1990. Neste sentido, diversos estudos sobre a influência dessas grandes redes foram realizados para a América Latina, com destaque para países como Argentina (MINAGRI, 2013), Brasil (FLEXOR, 2014), Chile (SEGUEL, 2016), México (GASCA e TORRES, 2014; OROZCO-HERNANDEZ, 2014), Nicarágua (ELDER e DAUVERGNE, 2015; MICHELSON, 2013).

A participação das cinco principais cadeias sobre as vendas totais dos supermercados era superior a $70 \%$ em toda a América Central, chegando a atingir 96\% na Costa Rica e 99\% na Guatemala, já no início dos anos 2000 , como se observa na tabela 2. As multinacionais do setor supermercadista correspondem a 80\% na capacidade de venda na Argentina, México, Costa Rica e Colômbia e mais de $90 \%$ no Brasil e Guatemala. A exceção é o Chile, onde o capital nacional prevalece, e ainda com o diferencial de que cadeia chilena liderada pela Cencosud é uma importante multinacional do setor e está entre os líderes desse segmento.

Tabela 2 - Internacionalização do comércio varejista na América Latina (Participação em \%) - Ano base 2003.

\begin{tabular}{cccc}
\hline Países & $\begin{array}{c}\text { Participação das cinco maiores } \\
\text { redes sobre as vendas totais de } \\
\text { supermercados }\end{array}$ & $\begin{array}{c}\text { Participação de multinacionais } \\
\text { sobre as vendas totais de } \\
\text { supermercados }\end{array}$ & $\begin{array}{c}\text { Participação de multinacionais } \\
\text { sobre as vendas das cinco } \\
\text { maiores redes }\end{array}$ \\
\hline Argentina & 76 & 64 & 84 \\
México & 80 & 71 & 89 \\
Chile & 55 & 10 & 18 \\
Costa Rica & 96 & 85 & 89 \\
Brasil & 47 & 43 & 91 \\
Panamá & 70 & nd. & 33 \\
El Salvador & 85 & 28 & 83 \\
Colômbia & 72 & 60 & 94 \\
Guatemala & 99 & 93 & 46 \\
Honduras & 71 & 33 & \\
\hline
\end{tabular}

Fonte - Adaptado de Reardon \& Berdegué (2002).

Apesar desse cenário observado na região, um contrapondo pode ser percebido na tabela 3, pelo estudo realizado pela Consultoria Nielsen (2015) que aponta a importância dos estabelecimentos de varejo tradicional nos países da América Latina. Embora a participação do setor supermercadista seja inferior a das demais regiões globais, sua taxa de crescimento é apontada como uma das mais elevadas, com um crescimento nas vendas em grandes supermercados em média $10 \%$ entre os anos pesquisados. 
Tabela 3 - Percentual do Comércio Varejista por canal de comercialização 2014/2015.

\begin{tabular}{|c|c|c|c|c|c|}
\hline Estabelecimentos & América Latina & $\begin{array}{c}\text { América do } \\
\text { Norte }\end{array}$ & Europa & $\begin{array}{c}\text { Ásia } \\
\text { Pacífico }\end{array}$ & Oriente Médio/África \\
\hline Hipermercados & $11 \%$ & $32 \%$ & $24 \%$ & $18 \%$ & $1 \%$ \\
\hline Grandes Supermercados & $13 \%$ & $41 \%$ & $25 \%$ & $11 \%$ & $33 \%$ \\
\hline Pequenos Supermercados & $18 \%$ & $0 \%$ & $17 \%$ & $12 \%$ & $5 \%$ \\
\hline Tradicional & $34 \%$ & $0 \%$ & $8 \%$ & $38 \%$ & $42 \%$ \\
\hline Conveniência & $1 \%$ & $20 \%$ & $6 \%$ & $7 \%$ & $4 \%$ \\
\hline Drogarias & $9 \%$ & $7 \%$ & $4 \%$ & $5 \%$ & $6 \%$ \\
\hline Lojas de desconto & $0 \%$ & $1 \%$ & $11 \%$ & $0 \%$ & $0 \%$ \\
\hline Quiosques & $6 \%$ & $0 \%$ & $1 \%$ & $1 \%$ & $1 \%$ \\
\hline Bares & $5 \%$ & $0 \%$ & $0 \%$ & $2 \%$ & $4 \%$ \\
\hline Outros & $4 \%$ & $0 \%$ & $4 \%$ & $7 \%$ & $4 \%$ \\
\hline Total $\left(^{*}\right)$ & $100 \%$ & $100 \%$ & $100 \%$ & $100 \%$ & $100 \%$ \\
\hline
\end{tabular}

Fonte - Nielsen Retail Measurement Data (2015).

$\left({ }^{*}\right)$ Valores percentuais arredondados sem casas decimais.

Os conceitos de comércio moderno e comércio tradicional também estão se tornando difusos e imprecisos. A própria classificação de hipermercados, baseada em número de check-outs e metragens de área comercial, pode deixar de fazer sentido com o crescimento do comércio eletrônico de pronta entrega.

As distinções que ainda parecem ser relevantes não se relacionam à tecnologia ou escala comercial, mas à divisão do trabalho e concentração do capital. A complementaridade comercial com outros estabelecimentos comerciais é baixa; restrita em alguns casos a estabelecimentos prestadores de serviços (lanchonetes, loterias, bancas de jornais e revistas, lavanderias,serviços bancários, farmácias) nas grandes lojas.

As atividades de varejo alimentar, por sua vez, como lojas de frutas e verduras, açougues e panificados foram internalizados para dentro dos supermercados e não prosperaram como estabelecimentos independentes. O poder de mercado é apropriado majoritariamente pelo supermercado, que compete apenas com estabelecimentos de mesmo porte. Por outro lado, os mercados "tradicionais", que reúnem diversos comerciantes com porte comercial e produtos similares em competição ou produtos complementares, dividem entre si os ganhos de atração de consumidores dados pela marca ou tradição do mercado. Nestes casos, o ponto comercial (visibilidade e facilidade de acesso) agrega valores e ganhos diferenciais para os comerciantes (CEPAL, 2013; SACCO DOS ANJOS e CALDAS, 2017; COCATO, 2020).

A dinâmica de expansão dos supermercados na América Latina teve como consequência direta a perda de espaço e de importância comercial de mercados tradicionais e de pequenos mercados, bem como uma redução da importância das feiras livres nos maiores países (REARDON e BERDEGUÉ, 2002). Os dados para o caso brasileiro, confirmam esta tendência. Entre um extremo e outro, situam-se os diversos equipamentos de abastecimento alimentar (MENEZES, PORTO e GRISA, 2015). Até que a revolução tecnológica e comportamental dos hábitos de consumo baseados nas redes sociais reconfigure novamente este quadro.

\section{ABASTECIMENTO E COMÉRCIO VAREJISTA NO BRASIL}

A representatividade econômica do setor de supermercados no Brasil é muito expressiva. De acordo com a pesquisa Nielsen/ABRAS, em 2014 o setor tinha 38.317 lojas, 168.906 check-outs, 16,1 milhões de metros quadrados de área comercial, atingindo vendas brutas nominais anuais de $R \$$ 273,7 bilhões (equivalente a US $\$ 75,8$ bilhões, em março de 2016). Em 2014, os 20 maiores supermercados brasileiros foram responsáveis por $61 \%$ do faturamento do setor. Com $13 \%$ das lojas, ocupam $37 \%$ da área de venda total, indicando um tamanho médio operacional de grande porte, como se observa na tabela 4.

$\begin{array}{lllll}\text { Caminhos de Geografia } \quad \text { Uberlândia-MG } & \text { v. 23, n. } 85 & \text { fev./2022 } & \text { p. 88-101 Página } 92\end{array}$


Tabela 4 - Brasil: Supermercados por grupos de tamanho, faturamento, número de lojas, check-outs e área de vendas (2015).

\begin{tabular}{|c|c|c|c|c|c|c|c|c|}
\hline Categorias & $\begin{array}{c}\text { Faturamento } \\
\text { estimado US\$ } \\
\text { Bilhões }\end{array}$ & (\%) & $\begin{array}{l}\text { Número } \\
\text { de Lojas }\end{array}$ & (\%) & $\begin{array}{c}\text { Número } \\
\text { Check-Outs }\end{array}$ & (\%) & $\begin{array}{l}\text { Área de vendas } \\
\text { milhões de } \mathrm{m}^{2}\end{array}$ & (\%) \\
\hline Supermercados & 75,8 & $100 \%$ & 38.317 & $100 \%$ & 168.906 & $100 \%$ & 16,1 & $100 \%$ \\
\hline 500 maiores & 66,4 & $88 \%$ & 7.638 & $20 \%$ & 78.022 & $46 \%$ & 9,4 & $58 \%$ \\
\hline 300 maiores & 65,0 & $86 \%$ & 7.261 & $19 \%$ & 75.432 & $45 \%$ & 9,1 & $57 \%$ \\
\hline 20 maiores & 46,5 & $61 \%$ & 4.824 & $13 \%$ & 47.164 & $28 \%$ & 5,9 & $37 \%$ \\
\hline
\end{tabular}

Fonte - Abras (2015). Adaptação dos autores.

Ainda que estes dados possam ser elevados, os índices de concentração do setor supermercadista no Brasil são significativamente inferiores aos dos maiores países latino-americanos (México, Argentina e Colômbia). Alguns fatores explicariam este padrão, como a dimensão do país e a importância das redes regionais de supermercados que são bastante importantes em diversas regiões brasileiras. No entanto, as análises setoriais indicam que existe uma tendência de maior concentração neste setor (FGV, 2011).

Até meados da década de 1990, o Brasil tinha apenas uma única rede de supermercados de capital estrangeiro, o Carrefour, que permaneceu por muitos anos como líder de vendas, através de um plano de expansão com a compra de pequenas redes locais. Na verdade, este foi o início de uma "guerra" que colocou o Brasil em uma competição em escala global entre as grandes empresas de distribuição (BELIK e SANTOS, 2002). Atualmente, os quatro maiores supermercados no Brasil são controlados por capital estrangeiro: Companhia Brasileira de Supermercados (Extra/Pão de Açúcar), controlada pelo grupo francês Casino, Carrefour (França), Walmart (EUA) e Cencosud (Chile). A tabela 5 traz o rankeamento dos supermercados no Brasil, evidenciando a musculatura que esse setor apresenta.

Tabela 5 - Brasil: Dez maiores redes de Super e Hiper mercados por origem do capital, faturamento e número de lojas (2015).

\begin{tabular}{ccccc}
\hline №. & Rede de Super e Hiper & Origem do capital & $\begin{array}{c}\text { Vendas brutas } \\
(\mathbf{e m ~ R} \mathbf{\$} \text { bilhões) }\end{array}$ & Número de Lojas $^{(*)}$ \\
\hline 1 & Companhia Brasileira de Distribuição $_{2}$ & França / Brasil & 76,933 & 2.181 \\
2 & Carrefour(*) & França & 42,701 & 288 \\
3 & Walmart & EUA & 29,323 & 485 \\
4 & Cencosud & Chile & 9,267 & 222 \\
5 & Zaffari & Brasil & 4,508 & 31 \\
6 & Irmãos Muffato & Brasil & 4,095 & 44 \\
7 & Supermercados BH & Brasil & 3,972 & 149 \\
8 & SDB Comércio & Brasil & 3,883 & 52 \\
9 & Condor Super Center & Brasil & 3,815 & 41 \\
10 & Sonda Supermercados & Brasil & 3,110 & 39 \\
\hline
\end{tabular}

Fonte - Associação Brasileira de Supermercados ABRAS. Ranking (2015).

(*) Não divulga todos os dados.

$\left.{ }^{* *}\right)$ Valores não deflacionados.

Os indicadores mais adequados para mensurar a importância relativa dos diversos tipos de varejo alimentar são as pesquisas de hábitos de consumo por local de compra. A Pesquisa de Orçamentos Familiares (POF/IBGE) avalia por meio de pesquisa primária o número de aquisições de produtos de consumo no domicílio, segundo os locais de compras (BRASIL, 2009). De acordo com a pesquisa, para o ano de 2002, o equivalente a $36 \%$ dos atos de compras (número de transações) de alimentos no Brasil foi realizado em supermercados, índice que se eleva para próximo de $47 \%$ em 2008. Um crescimento de $28 \%$ em apenas seis anos, como se observa na tabela 6. 
Tabela 6 - Brasil: Percentual das aquisições de alimentos por tipo de estabelecimento (2003-2009).

\begin{tabular}{|c|c|c|c|}
\hline Locais de Compra & $2003(\mathrm{em} \%)$ & 2009 (em\%) & $\Delta \%(2003-2009)$ \\
\hline Supermercado e hipermercado & 36,5 & 46,9 & $28 \%$ \\
\hline Padaria e confeitaria & 14,0 & 13,8 & $-2 \%$ \\
\hline Mercearia e armazém & 18,8 & 18,8 & $0 \%$ \\
\hline Bar, lanchonete e restaurante & 1,6 & 1,3 & $-18 \%$ \\
\hline Feira livre & 5,4 & 5,0 & $-6 \%$ \\
\hline Ambulante & 2,2 & 2,0 & $-11 \%$ \\
\hline Outros & 21,5 & 12,2 & $-43 \%$ \\
\hline Total Alimentação no Domicilio & 100,0 & 100,0 & 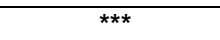 \\
\hline
\end{tabular}

Fonte - IBGE - Pesquisa de Orçamentos Familiares (2009). Elaborado pelos autores.

A desagregação dos dados por grupos de alimentos - produtos hortigranjeiros, produtos de origem animal, alimentos preparados e pré-processados e alimentos industrializados - possibilita compreender a importância do setor supermercadista como local de compra de referência de alimentos.

Os supermercados são o principal local de compras (estimados pelo número de aquisições) para quase todos os produtos alimentares, inclusive para os produtos hortigranjeiros, com $40 \%$ do número de compras de legumes e verduras, $43 \%$ de frutas e $47 \%$ de tubérculos. Entre os produtos frescos são significativos os indicadores de número de compras para aves e ovos (42\%), produtos lácteos $(50 \%)$ e carnes (52\%). A Figura 1 ilustra esse perfil de compras junto aos estabelecimentos varejistas no Brasil.

Os dados da pesquisa da POF 2008/2009 indicam que o setor supermercadista se consolidou e cresceu como local de compras de uma maneira geral, em relação ao levantamento anterior de 2002/2003, sendo líder em praticamente todos os tipos de alimentos. As exceções são para produtos como pães (padarias são o local preferido) e pescados comercializados em estabelecimentos especializados na categoria "outros estabelecimentos".

Entre os anos de 2003 e 2009 o número de aquisições relacionadas ao setor de supermercados aumentou para todos os tipos de alimentos $\mathrm{e}$ as maiores taxas ocorreram em produtos hortigranjeiros e produtos de origem animal. A figura 1 evidencia a supremacia dos supermercados em todos os itens comercializados, de acordo com os dados da POF.

Figura 1 - Porcentagem do número de Aquisições por tipo de alimentos em estabelecimentos varejistas (2009).

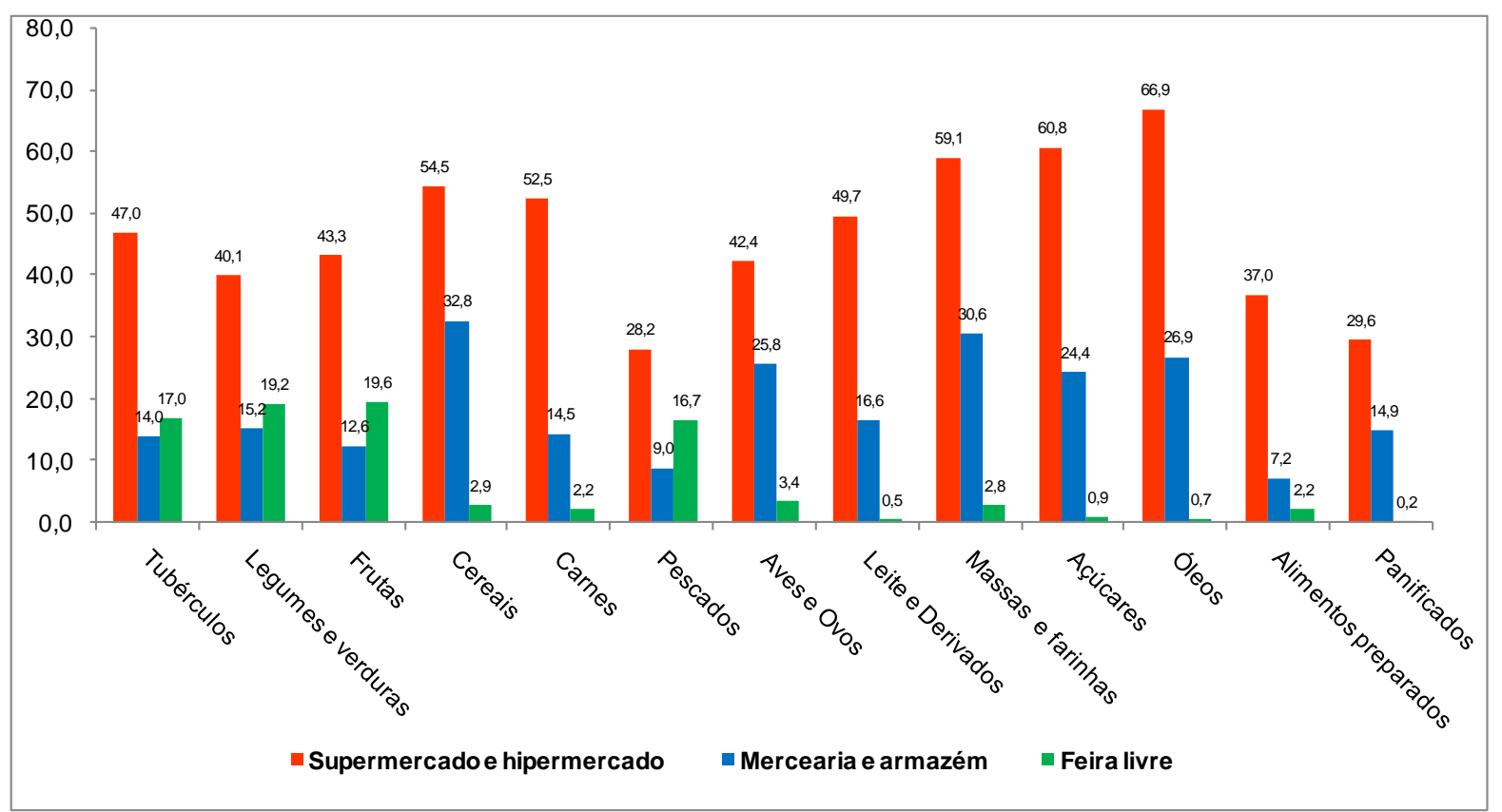

Fonte - IBGE - Pesquisa de Orçamentos Familiares, 2009. Elaboração dos autores.

$\begin{array}{lllll}\text { Caminhos de Geografia } & \text { Uberlândia-MG } & \text { v. 23, n. } 85 & \text { fev./2022 } & \text { p. 88-101 Página } 94\end{array}$


O número de aquisições em pequenos mercados cresce para hortigranjeiros e produtos de origem animal, mas diminui para os demais. Os grandes perdedores neste processo foram as feiras livres, o comércio informal e "outros estabelecimentos", que reúnem lojas de comércio especializado, como lojas de frutas e verduras (sacolão e varejão), açougues e peixarias e lojas de conveniência ${ }^{1}$. A tabela 7 permite observar o crescimento nas compras realizadas pelas famílias junto aos supermercados, para todos os alimentos considerados na pesquisa.

Tabela 7 - Brasil: Variação no número de compras em supermercados e hipermercados por grupo de alimentos (2003-2009).

\begin{tabular}{|c|c|c|c|c|c|c|}
\hline $\begin{array}{l}\text { Tipos de Produtos Locais } \\
\text { de compra }\end{array}$ & $\begin{array}{c}\text { Super e } \\
\text { Hipermercados }\end{array}$ & $\begin{array}{l}\text { Pequenos } \\
\text { mercados }\end{array}$ & Padarias & $\begin{array}{l}\text { Feiras } \\
\text { Livres }\end{array}$ & Ambulantes & $\begin{array}{l}\text { Outros } \\
\left.\text { Estab. } .^{*}\right)\end{array}$ \\
\hline Legumes e Verduras & $38 \%$ & $12 \%$ & - & $-8 \%$ & $-21 \%$ & $-32 \%$ \\
\hline Tubérculos & $42 \%$ & $18 \%$ & $4 \%$ & $-6 \%$ & $-39 \%$ & $-41 \%$ \\
\hline Frutas & $41 \%$ & $13 \%$ & - & $-13 \%$ & $-35 \%$ & $-28 \%$ \\
\hline Cereais & $34 \%$ & $10 \%$ & $-20 \%$ & $-6 \%$ & $-11 \%$ & $-65 \%$ \\
\hline Carne & $29 \%$ & $5 \%$ & $-12 \%$ & - & - & - \\
\hline Pescado & $53 \%$ & $23 \%$ & $8 \%$ & - & - & - \\
\hline Aves e Ovos & $29 \%$ & $10 \%$ & $-11 \%$ & - & - & - \\
\hline Leite e Produtos lácteos & $38 \%$ & $11 \%$ & $17 \%$ & - & - & - \\
\hline Massas e Farinhas & $25 \%$ & $-6 \%$ & $-7 \%$ & - & - & - \\
\hline Panificados & $26 \%$ & $-3 \%$ & $-7 \%$ & - & - & - \\
\hline Conservas & $17 \%$ & $-11 \%$ & $7 \%$ & - & - & - \\
\hline Alimentos preparados & $23 \%$ & $-8 \%$ & $-1 \%$ & - & - & - \\
\hline Azeites e óleos & $24 \%$ & $-6 \%$ & $15 \%$ & - & - & - \\
\hline Açúcares & $19 \%$ & $-9 \%$ & $36 \%$ & - & - & - \\
\hline Bebidas & $20 \%$ & $-9 \%$ & $-24 \%$ & - & - & - \\
\hline
\end{tabular}

Fonte - IBGE - Pesquisa de Orçamentos Familiares (2009). Elaborado pelos autores.

$\left(^{\star}\right)$ A categoria "Outros" inclui açougues, peixarias, sacolões e diversos pontos de venda varejista.

A importância dos supermercados como local de compras de produtos hortigranjeiros reflete um fenômeno recente. Consolidou-se com a sua entrada do setor no segmento de hortifrutis, bem como no comércio de frutas, legumes e verduras (ou "FLV", de acordo com a moderna nomenclatura), que incluem tubérculos e raízes.

Esse avanço do setor supermercadista é resultado de alguns fatores importantes. O primeiro referese ao aspecto de conveniência e atração de consumidores por meio de promoções, estimulando os consumidores a comprarem um conjunto mais diversificado de bens. $\mathrm{O}$ caráter de perecibilidade dos produtos hortigranjeiros é utilizado como estímulo para aumentar a frequência dos consumidores nos supermercados em busca de frescor ou de promoções.

A área ocupada pela seção de FLV nos supermercados normalmente tem um padrão diferente dos demais produtos, com maior espaçamento entre as gôndolas e área de passagem ampla e aberta, possibilitando que os consumidores visualizem as propagandas e promoções de outros produtos. Segundo Belik e Chaim (1999), um supermercado de porte médio reserva 10,5\% da sua área de venda para os hortifrutis. Este setor, de acordo com os autores, contribui com $7,5 \%$ do seu faturamento anual.

\footnotetext{
1 É necessário destacar que este comportamento não pode ser associado unicamente ao dinamismo comercial dos supermercados. O período analisado indica uma particularidade da economia brasileira, marcada pelo crescimento da renda e diminuição da desigualdade. Segundo o IPEA (2012), desde o fim de 2003, a economia cresceu em todos os anos, compondo uma taxa acumulada de 40,7\% até 2011. Neste período, a taxa de crescimento do PIB per capita acumulada foi de $27,7 \%$, e a renda domiciliar per capita cresceu $40 \%$, e a taxa de redução da pobreza foi de $57,5 \%$.
} 
O segundo fator é a resposta aos novos hábitos de consumo, que valoriza os aspectos relacionados à saúde e dieta saudável. Em pesquisa qualitativa direta realizada pela Nielsen/ABRAS (2015) foi apontado que $16 \%$ dos maiores estabelecimentos supermercadistas no Brasil comercializam produtos orgânicos em suas seções de FLV. O terceiro fator é comercial. De acordo com o ranking construído pela Nielsen/ABRAS (2015), o setor de FLV foi responsável por $6,8 \%$ do faturamento bruto dos supermercados no Brasil, considerados todos os segmentos comerciais, o que representa um faturamento de $R \$ 18,61$ bilhões anuais (equivalente a $U \$ 4,81$ bilhões, em março de 2016).

No entanto, é importante destacar que o setor supermercadista trata-se de um canal de comercialização muito seletivo para os produtores rurais. Em pesquisa realizada pela Revista Hortifruti Brasil (2010), produtores rurais fornecedores de supermercados, apontaram três vantagens referentes ao fornecimento para supermercados: (1) adimplência (pagamento certo); (2) liquidez e venda em grandes volumes e (3) estabilidade de preços, sendo que as grandes redes não costumam seguir a alta volatilidade dos preços do atacado.

Por outro lado, a relação de desvantagens apontadas pelos produtores para venda direta aos supermercados indica a seletividade deste canal de distribuição. Primeiro, pela ocorrência de descontos e bonificações. Os descontos são solicitados (aos produtores) em várias épocas do ano, como em aniversários, inaugurações e promoções das lojas. A bonificação é um desconto financeiro ou em mercadoria, que pode variar entre $5 \%$ e $20 \%$ sobre o valor da negociação, dependendo do porte da rede. Em segundo, o prazo de pagamento que nas grandes redes de supermercados pode variar de 40 a 60 dias, sendo maior do que o prazo de outros clientes. E em terceiro, a devolução de mercadoria em função do não cumprimento do padrão estabelecido pelo supermercado. No atacado tradicional, é comum haver um deságio pelo produto fora de padrão, mas dificilmente há devolução.

Outro fator é a exigência de produtos rastreados e certificados. Estes produtos rastreados e de qualidade (aspecto satisfatório, classificação) não conseguem obter uma valorização adicional (prêmio) em relação aos seus preços, porque tais características já fazem parte das exigências do supermercado. Dessa forma, a única vantagem que o fornecedor obtém é a prioridade de venda, não obtendo nenhum lucro ou remuneração diferenciada por tais mercadorias com essa diferenciação.

Em suma, estas condições selecionam não apenas os produtos, mas os produtores (individuais ou associados) mais organizados e tecnificados, aqueles que têm capacidade econômica para suportar os custos de transação que estão envolvidos na absorção total do risco comercial (CUNHA, 2010). O espaço para produtos da agricultura familiar nestas condições é muito restritivo.

\section{CANAIS VAREJISTAS TRADICIONAIS}

Ainda que os supermercados tenham importância crescente no varejo alimentar brasileiro, os estabelecimentos tradicionais, como os varejistas de FLV, feiras e vars públicos ainda têm expressividade.

No Brasil, o modelo de distribuição das centrais de abastecimento levou à criação de um modelo peculiar de venda varejista de produtos hortigranjeiros, conhecido como "sacolão". Este tipo de comércio varejista é caracterizado pela venda de um conjunto de produtos hortifrutícolas, que compõem um mix básico, a um preço único, sendo que comercializa também outros produtos e variedades com preços diferenciados, geralmente frutas nacionais ou importadas.

As características do modelo varejista do "sacolão" estão associadas ao modo de operação atacadista baseada nos seguintes aspectos: (1) compra em grande escala com poder de barganha de preços, ou mesmo a verticalização comercial do atacado para o varejo; (2) pagamento do produto a prazo e venda à vista no varejo; (3) a estratégia de preços que garante sobrelucro nos produtos em período de safra.

A estes fatores, relacionados à lógica atacadista do modelo "sacolão", juntam-se vantagens típicas da operação varejista, associadas à composição do mix do preço único e da relação com os consumidores: a criação de uma clientela diária, devido à acessibilidade espacial dos "sacolões", os ganhos de escala de distribuição, devido à figura única do atacadista e varejista e a rapidez do processo de compra, facilitando maior fluxo de consumidores pela agilidade do auto-serviço do preço único. Este modelo avançou no espaço comercial anteriormente ocupado pelas feiras livres e dos mercados públicos tradicionais.

No caso das feiras livres esse modelo de comércio surgiu no Brasil juntamente com o avanço das cidades, existindo desde o tempo colonial e persistem nos dias atuais com um espaço cada vez mais restrito nos grandes centros, em termos de tamanho e relevância no abastecimento. No entanto, em

$\begin{array}{lllll}\text { Caminhos de Geografia } & \text { Uberlândia-MG } & \text { v. 23, n. } 85 & \text { fev./2022 } & \text { p. 88-101 Página } 96\end{array}$


alguns municípios brasileiros, as feiras fazem parte de um referencial cultural e social, tanto como espaço comercial para produtos típicos, como em termos de relações sociais e espaços de convivência.

Já o surgimento de mercados públicos ocorre a partir da segunda metade do século XIX, com o avanço da urbanização, por meio da construção de mercados municipais de grande porte nas grandes cidades. Gradativamente os antigos mercados municipais foram sendo desativados ou substituídos por outros equipamentos de abastecimento, mas ainda hoje são importantes equipamentos e abastecimento em cidades médias (BELIK, 2004). O universo e o perfil, tanto das feiras livres como dos mercados públicos, ganharam contornos distintos com o decorrer do tempo, mas não deixaram de ocupar os espaços de comercialização de produtos do sistema agroalimentar.

A enquete MapaSan realizada no Brasil pelo Ministério do Desenvolvimento Social (MDS), em 2015 junto aos conselhos municipais de segurança alimentar e nutricional levantou a existência de feiras livres e mercados municipais e mercados públicos com preços regulados ("sacolões públicos"). Foram identificadas 6.073 feiras livres em 1.767 municípios brasileiros, 885 mercados municipais e 133 "sacolões" públicos, como se observa na tabela 8.

Tabela 8 - Brasil: Tipo de estabelecimento varejista por porte dos municípios registrado no MapaSan (2015).

\begin{tabular}{|c|c|c|c|c|c|c|c|c|}
\hline \multirow[b]{2}{*}{ Equipamentos de abastecimento } & \multicolumn{7}{|c|}{ Municípios por população (IBGE) } & \multirow[b]{2}{*}{ Total } \\
\hline & $\begin{array}{c}\text { Até } \\
5.000 \\
\text { hab. }\end{array}$ & $\begin{array}{c}\mathrm{De} \\
5.001 \mathrm{a} \\
10.000 \\
\text { hab. }\end{array}$ & $\begin{array}{c}\text { De } \\
10.001 \\
\text { a } \\
20.000 \\
\text { hab. }\end{array}$ & $\begin{array}{c}\text { De } \\
20.001 \\
\text { a } \\
50.000 \\
\text { hab. }\end{array}$ & $\begin{array}{c}\text { De } \\
50.001 \mathrm{a} \\
100.000 \\
\text { hab. }\end{array}$ & $\begin{array}{c}\text { De } \\
100.001 \mathrm{a} \\
500.000 \\
\text { hab. }\end{array}$ & $\begin{array}{c}\text { Acima de } \\
500.000 \\
\text { hab. }\end{array}$ & \\
\hline №. de Municípios com Feiras & 186 & 307 & 485 & 429 & 157 & 171 & 32 & 1.767 \\
\hline №. de Feiras & 199 & 361 & 679 & 828 & 478 & 1411 & 2117 & 6.073 \\
\hline Média de Feiras por município & 1,1 & 1,2 & 1,4 & 1,9 & 3,0 & 8,3 & 66,2 & 3 \\
\hline Mercado Público & 61 & 128 & 237 & 250 & 94 & 91 & 24 & 885 \\
\hline Sacolões Públicos & 21 & 22 & 34 & 26 & 12 & 11 & 7 & 133 \\
\hline
\end{tabular}

Fonte - SGI/MDS. Base de dados MapaSan.

Base: 2.430 municípios responderam total ou parcialmente os quesitos, equivalem a 43,6\% dos municípios brasileiros.

O caso brasileiro é bastante ilustrativo sobre as tendências do setor de comércio varejista na América Latina em função das dimensões e desigualdades do país. Os dados sobre hábitos de consumo no Brasil demonstram o avanço do capital supermercadista sobre os diversos segmentos alimentares, como os FLV e produtos cárnicos e panificados, que eram um nicho comercial de estabelecimentos especializados.

A disputa por espaço e sobrevivência dos equipamentos tradicionais de abastecimento como feiras e mercados, depende da criação de novos atrativos e novos valores. Novos valores (no sentido econômico) que expressem de forma indissociável a qualidade, a representação social ou local e a forma de transação, marcadas pela mediação da pessoalidade da escolha, da avaliação e da forma de negociação face à face.

A qualidade associa-se à valorização de elementos relacionados ao local de sua produção, às variedades ofertadas, à forma de produção e apresentação dos produtos, mesmo que seja baseada em julgamentos e avaliações qualitativas. É a preferência pelo típico, o artesanal ou o produto de pequena escala produtiva. A representação social e local reflete a valorização atribuída aos produtos que estabelecem conexões com as relações sociais envolvidas no processo produtivo. Ou seja, importa ou diferencia a origem do produto, a tradição da região e uma dose de identidade pessoal, familiar, comunitária.

O outro elemento desta configuração é a pessoalidade das relações comerciais, ao valorizar vínculos de confiança com o vendedor, seja o produtor, ou seu representante, fiador da qualidade ou detentor de "boa prosa". O jargão clássico da "agregação de valor ao produto" passa a ser tratado em uma nova dimensão, não apenas restrito ao atendimento a nichos de consumidores específicos.

$\begin{array}{llllll}\text { Caminhos de Geografia } & \text { Uberlândia-MG } & \text { v. 23, n. } 85 & \text { fev./2022 } & \text { p. 88-101 } & \text { Página } 97\end{array}$


Estes novos padrões de relações de consumo se desenvolveram e prosperaram simultaneamente em diversos países. Iniciativas como Food Miles, Slowfood, programas de articulação da gastronomia regional com produtos típicos e as compras governamentais de produtos locais são novas referências em abastecimento. Finalmente, a associação entre lazer e alimentação, valorizando os mercados e equipamentos tradicionais, é uma fonte importante de revalorização dos elementos culturais e locais nas cidades.

\section{CONSIDERAÇÕES FINAIS}

Os supermercados vêm dominando o mercado varejista alimentar na América Latina desde os anos de 1980, expandindo sua atuação em cidades médias e pequenas, em todos os países da região. O que está na base do modelo supermercadista é a competição baseada em margens reduzidas de lucro unitário e ganhos de escala. Operam com uma lógica contínua para redução de custos de produção e de transação, estruturada a partir de contratos com produtores rurais e atacadistas, negociação contínua com fornecedores para obtenção de menores preços e melhores condições.

Os supermercados são "famintos" quando se trata do comércio de alimentos. Os segmentos de frutas, legumes e verduras, açougues e panificados foram internalizados para dentro dos supermercados e não prosperaram como estabelecimentos independentes em seu entorno. No caso dos FLV, este interesse é explicado também pelo seu elevado potencial de atração de consumidores com hábitos de compra mais frequentes.

O impacto na cadeia de produção é expressivo. O modelo de compra dos supermercados estabelece padrões comerciais e técnicos que são muito seletivos em termos de escala comercial e de condições comerciais e de fornecedores. Esta seletividade afeta diretamente a diversidade da pauta de oferta de produtos regionais ou típicos que ainda não lograram alcançar uma escala comercial ou técnica. Outro aspecto da preponderância deste modelo refere-se à competição com outros estabelecimentos varejistas, como feiras livres, pequenos mercados, mercados municipais e também com centrais de abastecimento, que têm função varejista e que não conseguem acompanhar o ritmo de inovações, os ganhos de eficiência do modelo de gestão e os preços praticados dos supermercados.

Este novo e incerto cenário pode gerar possibilidades, alternativas e oportunidades para a inclusão de produtores e comerciantes de pequena escala no abastecimento alimentar das cidades, valorizando o componente das tradições e características regionais e locais. Para fortalecer o elo da produção agrícola, é necessária uma ação muito efetiva baseada na capacitação tecnológica e, sobretudo organizacional, de planejamento da produção e de capacitação para negociação comercial.

\section{AGRADECIMENTOS}

Este artigo é resultado de pesquisa financiada pelo Projeto de Educação Ambiental (PEA)-Pescarte que é uma medida de mitigação exigida pelo Licenciamento Ambiental Federal, conduzido pelo IBAMA.

\section{REFERÊNCIAS}

ABRAS, Revista Superhiper. Ano 42 no․ 478. Abril de 2016. Disponível em: www.abras.com.br. Acesso em 07/02/2019.

BELIK, W.; CHAIM, N. Formas híbridas de coordenação na distribuição de frutas, legumes e verduras no Brasil. Revista Cadernos de Debate. Campinas, v. 7, p. 1-9, 1999. https://doi.org/10.1111/1467$\underline{7679.00187}$

BELIK, W.; ROCHA, S. R. Regional Market Strategies of Supermarkets and Food Processor in Extended MERCOSUR. Development Policy Review. 20 (4):515-528, 2002.

BELIK, W. Supermercados e produtores: Limites, possibilidades e desafios. Congresso Brasileiro de Economia, Administração e Sociologia Rural, 42. Anais. Cuiabá, 2004.

$\begin{array}{lllll}\text { Caminhos de Geografia } & \text { Uberlândia-MG } & \text { v. 23, n. } 85 & \text { fev./2022 } & \text { p. 88-101 }\end{array}$ Página 98


BEZERRA, I. N. et al. Consumo de Alimentos fora do Lar no Brasil Segundo Locais de Aquisição. Revista de Saúde Pública. 51:15, 2017.

BICHIR, R. M. O Bolsa Família na berlinda? Os desafios atuais dos programas de transferência de renda. Novos Estudos CEBRAP, ํo 87, p. 115-129, 2010. https://doi.org/10.1590/S010133002010000200007

BOTTIGLIERI, M.; PETTENATI, G.; TOLDO, A. Toward the Turin Food Policy: Good practices and visions. Franco Angeli: Milano, 2016. Disponível em: http://www.cittadelbio.it/pdf/BOOK Turin food policy.pdf. Acesso em:14/06/2019. https://doi.org/10.3280/oa-156

BRASIL. Pesquisa de Orçamentos Familiares. Instituto Brasileiro de Geografia e Estatística. Rio de Janeiro. 2009.

BRASIL. Pesquisa anual do Comércio. Instituto Brasileiro de Geografia e Estatística. Rio de Janeiro. 2014.

BRASIL. MAPASAN - Mapeamento de Segurança Alimentar e Nutricional. Manual de Orientações, 2015. Disponível em www.mds.gov.br/sagicenso/mapasan2015/Brasília.

CEPAL. Agricultura Familiar y Circuitos Cortos. Nuevos esquemas de producción, comercialización y nutrición. Serie Seminarios y Conferencias: Memoria del seminario sobre circuitos cortos. Santiago, Chile, 2013.2 Disponível em: http://repositorio.cepal.org/bitstream/handle/11362/36832/S2014307 es.pdf?sequence $=1$ \&isAllowed= y. Acesso em: Acesso em 07/11/2018.

COCATO, G. P. Estabelecimentos Comerciais Varejistas no Aglomerado Urbano de Londrina: um estudo de caso. Revista Caminhos de Geografia - Uberlândia-MG v. 21, n. 75 Jun/2020 p. 34-51. https://doi.org/10.14393/RCG217550435

CUNHA, A. R.A. A. Abastecimento alimentar: a superação do padrão Velho-Obsoleto para o NovoAncestral. In: SCHNEIDER, S.; CRUZ, F. T.; MATTE, A. (Orgs.). Alimentos para Produtores e Consumidores: conectando novas estratégias de abastecimento de alimentos. Porto Alegre: Ed. UFRGS. pp.54-70. 2015.

O Sistema Atacadista Alimentar Brasileiro: origens, destinos [tese]. Campinas: Instituto de Economia - Unicamp; 162 p. 2010.

ELDER, S. D.; DAUVERGNE, P. Farming for Walmart: the politics of corporate control and responsibility in the global South. The Journal of Peasant Studies. Vol. 42, ISS. 5, 2015. https://doi.org/10.1080/03066150.2015.1043275. https://doi.org/10.1080/03066150.2015.1043275

FAO. Cooperación Internacional y Políticas Públicas de Seguridad Alimentaria y Nutricional. La experiencia del Programa España-FAO para América Latina y el Caribe, 2014. Disponível em: http://www20.iadb.org/intal/catalogo/PE/2013/13503.pdf. Acesso em: 14/07/2019.

FLEXOR, G. Las tiendas frente a la "revolución de los supermercados": el caso de la Región Metropolitana de Río de Janeiro. Economía, Sociedad y Territorio. Vol. 14(45):497-522, 2014. https://doi.org/10.22136/est002014384

GASCA, J. e TORRES, F. El Control Corporativo de la Distribución de Alimentos en México. Revista Problemas del Desarrollo, 176 (45), pp. 133-155, 2014. Disponível em: https://www.sciencedirect.com/science/article/pii/S0301703614708533. Acesso em: 21/05/2019. https://doi.org/10.1016/S0301-7036(14)70853-3

FGV. Análise Setorial: Supermercados. GVcev - Centro de Excelência em Varejo da FGV-EAESP, 2011.

HORTIFRUTI BRASIL. Ano 9. №. 94. Setembro de 2010.

IPEA. A Década Inclusiva (2001-2011): desigualdade, pobreza e políticas de renda. Comunicado o․ 155. 25 de setembro de 2012.

KIMENJU, S. C. et. al. Do Supermarkets Contribute to the Obesity Pandemic in Developing Countries? Public Health Nutrition. 18(17), pp.3.224-3.233, 2015. Disponível em: https://www.cambridge.org/core/services/aop-cambridge-

$\begin{array}{lllll}\text { Caminhos de Geografia } & \text { Uberlândia-MG } & \text { v. 23, n. } 85 & \text { fev./2022 } & \text { p. 88-101 }\end{array}$


core/content/view/67380CCE80178A414F2FE42009F2EE36/S1368980015000919a.pdf/do supermar kets contribute to the obesity pandemic in developing countries.pdf. Acesso em: 18/02/2019.

LEMOS, M. B.; CUNHA, A. R.A.A. Os fluxos de abastecimento no Sistema agroalimentar de Minas Gerais: o caso de Belo Horizonte. VII seminário sobre a economia mineira. Diamantina. Anais. Belo Horizonte. 1995.

MALIK, V. S., WILLETT, W. C.; HU, F. B. Global Obesity: trends, risk factors and policy implications. Nature Reviews Endocrinology. Vol.9, pp.13-27, 2013. Disponível em: https://www.nature.com/articles/nrendo.2012.199. $\quad$ Acessoem $\quad 02 / 02 / 2018$. https://doi.org/10.1038/nrendo.2012.199

MALUF, R. S. Abastecimento Alimentar no Brasil. Brasília: Plenária CONSEA, 2012. Disponível em: < file:///C:/Users/LNV/Downloads/abastecimento-alimentar-no-brasil\%20(5).pdf>Acesso em: 10dez. 2018.

MENEZES, F.; PORTO, S.; GRISA, C. Abastecimento Alimentar e Compras Públicas no Brasil: um resgate histórico. Centro de Excelência Contra Fome, 2015. Disponível em: http://www.mds.gov.br/webarquivos/publicacao/seguranca_alimentar/PAA_Institucional_Estudo1_Hist orico_lowres.pdf. Acesso em 10/03/2019.

MICHELSON, H. C. Small Farmers, NGOs, and a Walmart World: Welfare Effects of Supermarkets Operating in Nicaragua. American Journal of Agricultural Economics, Vol.95, Issue 3, 1, pp.628 649, https://doi.org/10.1093/ajae/aas139.2013. https://doi.org/10.1093/ajae/aas139

MINAGRI. El Supermercadismo Argentino. Informe de Coyuntura del Sector. Buenos Aires, №2. Febrero 2013.2 Disponível em: http://www.alimentosargentinos.gob.ar/contenido/sectores/niveldeactividad/08Ago 2012 supermerca do.pdf. Acesso em 02/02/2018.

NIELSEN. The Future of Grocery E-Commerce, Digital Technology and Changing Shopping Preferences Around the World. April 2015. Disponível em https://www.nielsen.com/content/dam/nielsenglobal/vn/docs/Reports/2015/NielsenGlobalE-commerce and The New Retail Report. April.2015. (Digital).pdf. Acesso em 05/02/2018.

OROZCO-HERNANDEZ, M. E. e GARCIA-LUNA-VILLAGRAN, G. A. Walmart en áreas Periurbanas de la Ciudad de Toluca, México: efectos sociales, económicos y territoriales. Convergencia: Revista de Ciencias Sociales, Vol. 21, pp. 93-116 2014. Disponível em: http://www.scielo.org.mx/pdf/conver/v21n64/v21n64a4.pdf. Acesso em 02/02/2018.

POPKIN, B. M. Nutrition, Agriculture and the Global Food System in Low and Middle Income Countries. Food Policy. Vol.47, pp.91-96, 2014. Disponível em: https://www.sciencedirect.com/science/article/pii/S030691921400075X. Acesso em: 14/05/2019. https://doi.org/10.1016/j.foodpol.2014.05.001

REARDON, T. A. Growing Food for Growing Cities: transforming food systems in an urbanizing world. Chicago Council on Global Affairs, 2015.

REARDON, T. and BERDEGUÉ, J. A. The Rapid Rise of Supermarkets in Latin America: Challenges and Opportunities for Development. Development Policy Review. Vol. 20 (N.4): pp.371-388, 2002. Disponível em: http://onlinelibrary.wiley.com/doi/10.1111/1467-7679.00178/full. Acesso em 07/02/2020. https://doi.org/10.1111/1467-7679.00178

SACCO DOS ANJOS, F. e CALDAS, N. V. A dinâmica dos canais curtos de comercialização: o caso do Projeto Campagna Amica na Itália. Revista Sociedade e Estado - Vol. 32, №. 3, Setembro/Dezembro 2017. https://doi.org/10.1590/s0102-69922017.32030010

SEGUEL, C. C. La urbanización de holdings empresariales en Chile 1990-2015: una industria de paisajes en serie. Revista Bibliográfica de Geografía y Ciencias Sociales. Vol. XXI, N. 1.171. Biblio 3W. Universidad de Barcelona, 2016. Disponível em: http://www.ub.edu/geocrit/b3w-1171.pdf. Acesso em 02/02/2018.

SILVA, O. M. T.; PONTES, R. N. Bolsa Família $X$ Salário na Reprodução Social de Famílias Pobres em Belém (PA). Revista de Políticas Públicas, São Luís, v. 22, n. 2, p. 1029-1046. 2018. DOI: http://dx.doi.org/10.18764/2178-2865.v22n2 p1029-1046. ttps://doi.org/10.18764/21782865.v22n2p1029-1046

$\begin{array}{lllll}\text { Caminhos de Geografia } & \text { Uberlândia-MG } & \text { v. 23, n. } 85 & \text { fev./2022 } & \text { p. 88-101 }\end{array}$


SOARES, S. e SÁTYRO, N. O Programa Bolsa Família: desenho institucional, impactos e possibilidades futuras. IPEA Texto para Discussão, № 1424. Brasília, 2009.

SOUZA, A. et. al. Alimentos mais Consumidos no Brasil: Inquérito Nacional de Alimentação 20082009. Revista de Saúde Pública. 47 (1 Supl): 190S-9S. 2013. https://doi.org/10.1590/S0034$\underline{89102013000700005}$

TRAILL, W. B. The Rapid Rise of Supermarkets? Development Policy Review. Oxford. 24 (2): 163174.2006. https://doi.org/10.1111/j.1467-7679.2006.00320.x. https://doi.org/10.1111/j.14677679.2006.00320.x

VIOLA, D. et. al. Overweight and Obesity: Can we reconcile evidence about supermarkets and fast food retailers for public health policy? Journal of Public Health Policy. 34(3): pp.424-438. 2013.

Recebido em: 18/09/2020

Aceito para publicação em: 19/05/2021 